\title{
Pengaruh Laju Kecepatan Potong Pada Proses Pemotongan Menggunakan Gas Cutting
}

\author{
Studi Kasus Kekasaran Permukaan Hasil Pemotongan
}

Plat Tebal $12 \mathrm{~mm}$

\author{
Eko Slamet Riyadi \\ Program Studi Teknik Mesin \\ Politeknik Negeri Banyuwangi \\ Jl. Raya Jember Km 13 Labanasem,Kabat, Banyuwangi \\ ekoslametriyadi@poliwangi.ac.id
}

\author{
Deqi Pajar Pratama \\ Program Studi Teknik Industri \\ Politeknik Negeri Banyuwangi \\ Jl. Raya Jember Km 13 Labanasem,Kabat, Banyuwangi \\ deqi@poliwangi.ac.id
}

\begin{abstract}
Abstrak - Pada proses pemotongan logam lembaran dengan menggunakan las gas cutting hasil akhir dari setiap proses pemotongan sangat dipengaruhi oleh beberapa parameter dari proses pemotongan itu sendiri. Penelitian ini bertujuan untuk mengetahui pengaruh laju kecepatan pemotongan terhadap kekasaran permukaan hasil pemotongan. Penelitian ini menggunakan metode eksperimen. Populasi yang diambil adalah baja plat lembaran ASTM A36. Plat dipotong menggunakan brander potong dengan menggunakan campuran gas LPG dan Oksigen, dengan memvariasikan laju kecepatan pemotongan $153 \mathrm{~mm} / \mathrm{menit}, 273 \mathrm{~mm} / \mathrm{menit}, 420 \mathrm{~mm} / \mathrm{menit}, 555$ $\mathrm{mm} / \mathrm{menit}, 725 \mathrm{~mm} / \mathrm{menit}$. Busur api, jarak busur api terhadap benda kerja dianggap variabel konstan. Kekasaran permukaan hasil pemotongan diukur dengan menggunakan surface roughness tester "Mahr Marsurf M300". Hasil Penelitian menunjukkan bahwa kekasaran permukaan semakin meningkat seiring kenaikan laju gerak pemotongan. Nilai kekasaran yang paling kecil dihasilkan pada variasi kecapatan $153 \mathrm{~mm} /$ menit yaitu sebesar 0.230 $\mu \mathrm{m}$.
\end{abstract}

Kata kunci - Laju Pemotongan, Gas Cutting, Kekasaran Permukaan, surface roughness tester

\section{PENDAHULUAN}

Proses pemotongan plat baja lembaran merupakan pekerjaan wajib dan paling banyak dilakukan dalam suatu proses manufaktur terutama berkaitan dengan pengerjaan material plat baja. Pemotongan plat baja lembaran biasanya dilakukan dengan menggunakan laser plasma cutting, gas cutting machine dan lain lain. Hasil akhir dari setiap proses pemotongan plat sangat dipengaruhi oleh beberapa parameter dari proses pemotongan itu sendiri, adapun parameter yang sangat berpengaruh yaitu : jarak busur api dengan benda kerja, besar busur api (Jika menggunakan gas cutting), dan laju kecepatan potong.

Pada lembaga pendidikan yang menyelenggarakan pendidikan vokasional dibidang manufaktur dan pengelasan tentu pemotongan plat baja merupakan suatu keharusan dan wajib ada pada kurikulum pembelajarannya. Proses pemotongan plat baja dilakukan dengan berbagai macam tujuan misalnya untuk proses pembuatan part tertentu, pemotongan plat untuk bahan pengujian, dan lain sebagainya. Dalam prosesnya tentu ada beberapa faktor penghambat atau faktor kendala terutama dari parameter parameter pemotongan itu sendiri sehingga hal ini dapat mengakibatkan: sisi permukaan hasil pemotongan kasar dan tidak rata, tepi hasil pemotongan berubah secara struktur teknisnya

Karakteristik permukaan suatu benda mempunyai peranan yang sangat penting dalam sebuah produk terutama produk logam. Kekasaran (Roughness) merupakan salah satu konfigurasi permukaan yang apabila kita lihat dengan bantuan suatu alat pembesar sebenarnya tidak serapi dan sehalus yang kita lihat oleh mata secara langsung. Profil permukaan terlihat tidak teratur jika dilihat dari penampang melintang. Kekasaran mencakup ketidakteraturan yang diakibatkan oleh perlakuan selama proses produksi. Kecepatan laju pemotongan 
yang rendah dalam proses pemotongan dengan menggunakan gas cutting las dapat menghasilkan permukaan potong yang halus, walaupun terkadang permukaan yang relatif kasarpun sudah mencukupi untuk spesifikasi tertentu. Kekasaran permukaan hasil pemotongan sangat dipengaruhi oleh besar laju gerak makan pemotongan, sehingga pemilihan setting laju gerak kecepatan potong akan menentukan nilai kekasaran permukaan hasil pemotongan.

Penelitian ini bertujuan untuk:

1. Mengetahui kelengkapan apa saja yang dibutuhkan untuk melakukan pemotongan plat baja dengan menggunakan gas cutting

2. Mengetahui persiapan apa saja yang dibutuhkan sebelum kita melakukan proses pemotongan dengan menggunakan gas cutting

3. Mengetahui pengaruh laju kecepatan pemotongan terhadap kekasaran permukaan hasil pemotongan

4. Membuat solusi berapa laju pemotongan ideal yang harus diambil agar permukaan plat hasil pemotongan mempunyai nilai kekasaran yang rendah terutama untuk proses pemotongan akhir benda kerja dimana hasil permukaan pemotongan akhir itu yang dibutuhkan.

Adapun manfaat yang bisa diperoleh dari penelitian ini meliputi:

1. Memberikan informasi terkait pengaruh laju kecepatan pemotongan terhadap kekasaran permukaan hasil pemotongan.

2. Penelitian ini dapat dipergunakan sebagai salah satu referensi bagi peneliti selanjutnmengetahui berapa laju kecepatan pemotongan yang ideal untuk mendapatkan nilai angka kekasaran permukaan hasil pemotongan yang rendah terhadap material plat lembaran ASTM A36 dengan menggunakan gas cutting LPG-Oksigen

\section{METODE PENELITIAN}

\subsection{Tempat dan waktu}

Penelitian ini dilaksanakan di laboratorium Program Studi Teknik Mesin. dimulai dari tahapan persiapan penelitian dalam hal mempersiapkan peralatan pendukung selama proses pengambilan data berlangsung, melakukan pemotongan dengan menggunakan bander potong dengan gas LPG dan Oksigen untuk selanjutnya dilakukan pencatatan laju waktu pemotongan, dan melakukan uji kekasaran dengan roughness test

\subsection{Alat dan Bahan}

1. Alat

Alat-alat yang digunakan dalam penelitian ini meliputi:

1. Cutting tip

2. Tabung oxygen

3. Regulator Oxygen

4. Tabung LPG

5. Regulator LPG

6. Selang

7. Pemantik Api

8. Pallu chipping

9. Sikat baja

10. Meja potong

11. Blander potong

12. Surface Roughness Tester MAHR Marsuf M 300

2. Bahan

Bahan-bahan yang digunakan dalam penelitian ini meliputi:

1. plat baja lembaran $12 \mathrm{~mm}$

2. LPG

3. Oksigen

\subsection{Alur Penelitian}

Penelitian dilakukan dengan urutan seperti diagram di bawah ini:

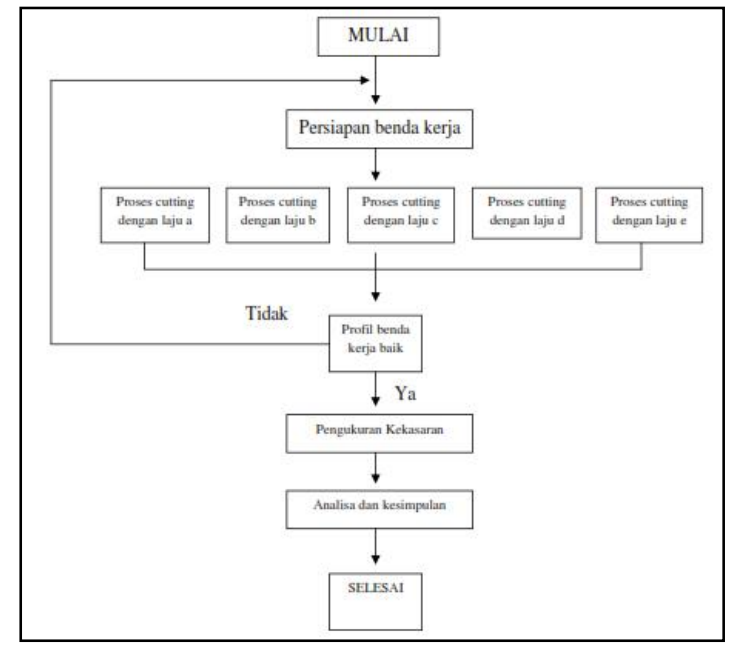

Gambar 2. Diagram Alir Penelitian

Percobaan ini dilakukan dengan design eksperimen. Populasi yang diambil adalah baja plat lembaran ASTM A36. Plat dipotong menggunakan brander potong dengan menggunakan campuran gas LPG dan Oksigen, dengan memvariasikan laju kecepatan pemotongan $153 \mathrm{~mm} /$ menit, 273 $\mathrm{mm} /$ menit, $420 \mathrm{~mm} /$ menit, $555 \mathrm{~mm} /$ menit, 725 $\mathrm{mm} /$ menit. Setiap masing-masing variasi kecepatan potong dilakukan pemotongan 3 sample benda uji, dari ketiga sample benda uji tersebut semuanya di ukur nilai kekasaran permukaan hasil pemotongannya untuk selanjutnya diambil satu data 
rata rata nilai kekasaran permukaan potong. Busur api, jarak busur api terhadap benda kerja dianggap variable konstan. Kekasaran permukaan hasil pemotongan diukur dengan menggunakan surface roughness tester "Mahr Marsurf M300".

\subsection{Kekasaran Permukaan}

Permukaan halus adalah salah satu karakteristik geometris yang ideal dari suatu komponen. Tapi dalam prakteknya sulit untuk mendapatkan suatu komponen dengan permukaan yang sangat halus. Hal ini disebabkan oleh beberapa faktor, misalnya faktor manusia (operator) dan faktor-faktor dari mesin-mesin yang digunakan untuk membuatnya. Dalam perencanaan suatu komponen mesin khususnya yang menyangkut masalah gesekan pelumasan, keausan, tahanan terhadap kelelahan, tingkat kehalusan suatu permukaan memang peranan yang sangat penting. Oleh karena itu, dalam perencanaan dan pembuatannya harus dipertimbangkan terlebih dulu mengenai peralatan mesin yang mana harus digunakan untuk membuatnya serta berapa ongkos yang harus dikeluarkan. Karakteristik permukaan ini harus dapat dipahami oleh perencana dan operator, agar tidak terjadi penyimpangan dalam proses pembuatannya. Gambar teknik digunkan sebagai komunikasi karakteristik permukaan. Akan tetapi untuk menjelaskan mengenai karakteristik suatu permukaan akan sulit. Walaupun saat ini sudah banyak parameter yang digunakan dalam pembahasan karakteristik permukaan, namun belum ada cara menjelaskan secara jelas mengenai keadaan yang sesungguhnya dari suatu permukaan.

\subsection{Batasan Permukaan dan Parameter- parameternya}

Batas yang memisahkan benda padat dengan sekitarnya, disebut permukaan. Dalam prakteknya, bahan yang digunakan untuk benda kebanyakan dari besi atau logam. Maka, benda-benda padat yang bahannya terbuat dari tanah, batu, kayu dan karet tidak akan disinggung dalam penelitian ini.

Istilah profil sering disebut dengan istilah lain yaitu bentuk. Pengukuran suatu permukaan tiga dimensi itu sulit. Maka untuk memudahkan pengukuran maka penampang permukaan perlu dipotong. Pemotongan ada empat cara yaitu pemotongan normal, serong, singgung dan pemotongan singgung dengan jarak kedalaman yang sama. Profil adalah istilah dari garis hasil pemotongan, dalam kaitannya dengan permukaan. Dalam analisisnya hanya dibatasi pada pemotongan secara normal. Gambar 7.1. menunjukkan perbedaan antara bidang dan profil.

\section{HASIL DAN DISKUSI}

\subsection{Pemotongan Logam dengan Las/Gas}

Prinsip pemotongan dengan Gas adalah proses memotong besi atau baja dengan menggunakan panas yang dihasilkan dari pembakaran reaksi kimia berupa gas. Memotong dengan cara memanaskan logam sampai mendekati titik lumer (cair) adalah proses pemotongan logam dengan gas. Kemudian potongan tersebut ditekan dengan semburan gas pada tekanan tertentu, sehingga logam yang akan mencair tersebut terbuang sehingga logam terpotong.

\subsection{Keuntungan dan kerugian pemotongan dengan gas}

Keuntungan memotong logam dengan gas :

Proses pemotongan yang cepat, hingga bentuk potongan hasilnya baik. Proses pemotongan dapat dilaukakan secara otomatis dengan mesin atau secara manual dengan tangan.

Kerugian memotong logam dengan gas :

Memerlukan alat dan perlengkapan yang khusus, harganya mahal. Perubahan struktur yang mengakibatkan perubahan sifat logam yang dipotong akan terjadi pada sisi bekas pemotongan.

Tahapan sebelum memulai pengambilan data adalah persiapan blander potong, meja bantu tempat penyangga rel blander potong harus di setting sedemikian rupa sehingga mempermudah dalam proses pemotongan.

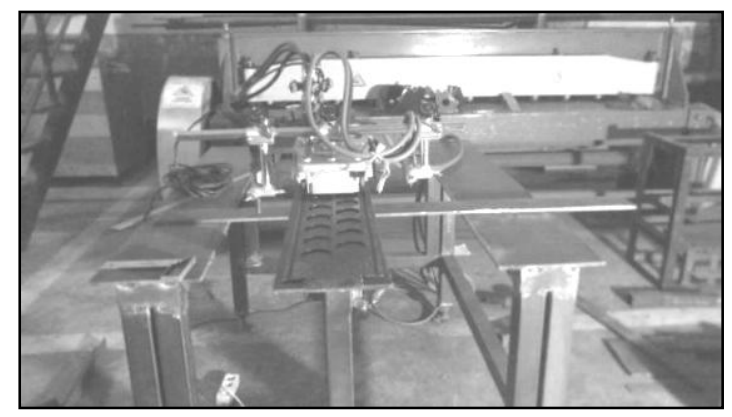

Gambar 4.1 Setting mesin blander potong 


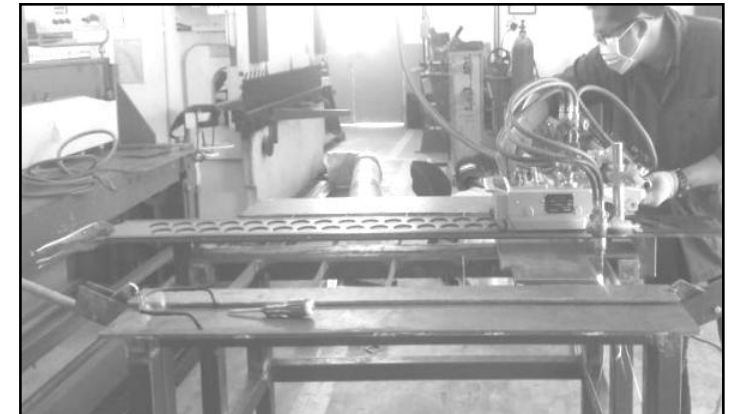

Gambar 4.2 Setting benda kerja di atas meja potong

Sebelum Proses pengambilan data dilakukan, terlebih dahulu dilakukan pemotongan plat lembaran dengan spesifikasi ASTM A36 untuk dijadikan beberapa sample pemotongan. Pemotongan dilakukan dengan cara benda kerja berupa plat lembaran dijepit pada meja pemotongan dan diposisikan sejajar dengan tepi sisi meja potong, selanjutnya nozzle cutting tip dari mesin blander potong diletakkan tegak lurus dengan benda kerja. Disini busur api, jarak busur api terhadap benda kerja dianggap variable konstan

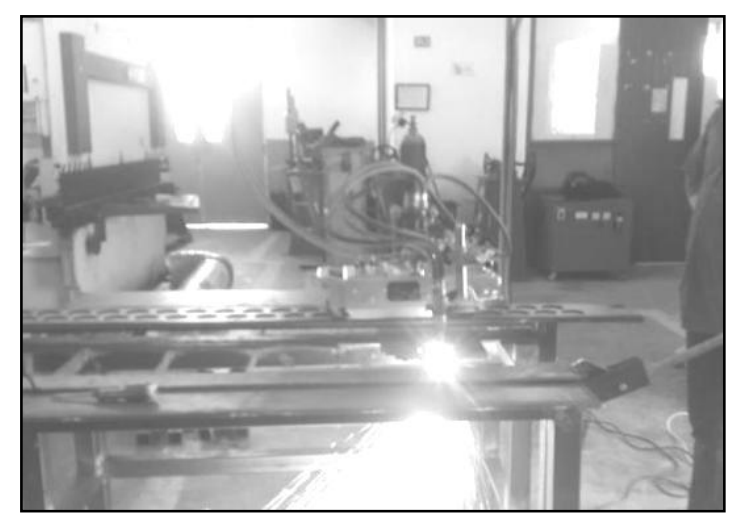

Gambar 4.3 Proses pemotongan benda kerja pengujian

Data laju kecepatan pemotongan ditunjukkan pada tabel 3.1 di bawah ini

Tabel 3.1 Laju Kecepatan Pemotongan

\begin{tabular}{|l|c|c|}
\hline No & $\begin{array}{c}\text { Kecepatan } \\
\text { pemotongan }\end{array}$ & $\mathbf{m m} /$ menit \\
\hline 1 & Kecepatan a & 153 \\
\hline 2 & Kecepatan b & 273 \\
\hline 3 & Kecepatan c & 420 \\
\hline 4 & Kecepatan d & 555 \\
\hline 5 & Kecepatan e & 725 \\
\hline
\end{tabular}

Tabel 3.1 Data variasi setting Laju Kecepatan pemotongan dalam $\mathrm{mm} / \mathrm{menit}$. Variasi laju kecepatan pemotongan pada tabel diatas didapatkan dari pengukuran langsung motor penggerak yang terpasang pada meja potong dan didapatkan 5 variasi kecepatan laju pemotongan dengan laju kecepatan mm untuk setiap menitnya seperti ditunjukkan pada tabel diatas. Sedangkan data hasil pengukuran kekasaran permukaan hasil pemotongan ditunjukkan pada tabel 3.2 kekasaran permukaan hasil pemotongan merupakan variabel terikat sedangkan variasi laju kecepatan pemotongan merupakan variabel bebasnya

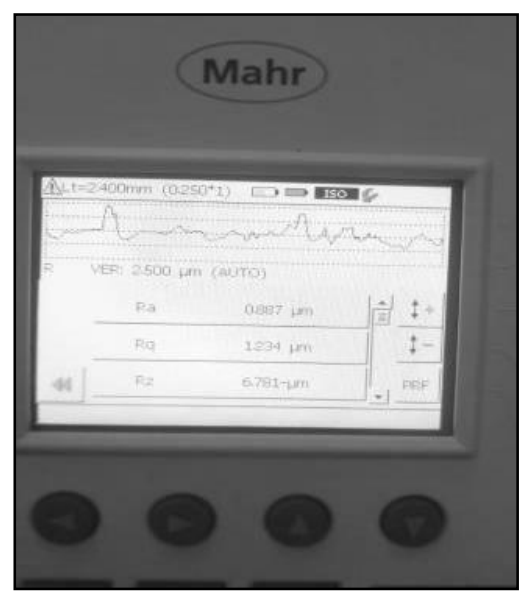

Gambar 4.4 Proses pegujian kekasaran sample dengan surface Roughnes Tester

Roughness/kekasaran didefinisikan sebagai ketidakhalusan bentuk yang menyertai proses produksi yang disebabkan oleh pengerjaan atau pemotongan. Nilai kekasaran dinyatakan dalam Roughness Average (Ra). Ra merupakan parameter kekasaran yang paling banyak dipakai secara internasional.

Pengukuran kekasaran permukaan diperoleh dari sinyal pergerakan stylus berbentuk diamond untuk bergerak sepanjang garis lurus pada permukaan sebagai alat indicator pengkur kekasaran permukaan benda uji. Prinsip kerja dari Surface Roughness adalah dengan menggunakan transducer dan diolah dengan mikroprocessor.

Langkah - langkah pengukuran dengan alat ini adalah :

1. Benda uji diletakkan pada meja datar.

2. Untuk melakukan pembacaan skala tekanan tehadap permukaan benda uji, ujung dari dial indicator di set pada posisi stabil.

3. Tentukan seberapa panjang dari bagian benda ukur yang akan di uji kekasaran permukaannya, nantinya panjang inilah yang akan di lewati oleh dial indicator.

4. Apabila dial indicator telah melakukan pengukuran sepanjang jarak yang kita tentukan, nilai kekasaran permukaan akan tercatat, dan dapat dilihat dalam bentuk print out. 
5. Sebelum dilakukan pengukuran, benda uji dan alat ukur telah diatur sehingga sedapat mungkin tidak terdapat kesalahan dalam pengukuran.

Klasifikasi kekasaran permukaan, yaitu:

1. Deskripsi statistik, adalah nilai rata-rata dan tinggi permukaan, contoh: Ra dan Rq.

2. Deskripsi nilai ekstrem, adalah nilai pada kondisi maksimum (Rv), dan kekasaran maksimum puncak ke lembah (Rmax)

3. Deskripsi tekstur, adalah panjang pengukuran (traversing length) $7.05 \mathrm{~mm}$, didapat 3 parameter yang telah diatur sebelum melakukan pengukuran. yaitu $\mathrm{Ra}$ (kekasaran rata-rata aritmatik), Rmax (kekasaran maksimum dari tinggi puncak dan lembah), Rz (kekasaran total rata-rata).

Tabel 3.2 dibawah menunjukkan hasil pengukuran angka kekasaran $\mathrm{Ra}$ dengan menggunakan alat surface roughness pada setiap laju kecepatan pemotongan. Pengukuran dilakukan pada 3 sample material uji pada setiap variasi laju kecepatan potong, dari pengukuran 3 sample material uji tersebut dijumlah untuk kemudian dirata rata sehingga didapatkan nilai rata - rata angka kekasaran dari 3 material sample uji untuk setiap variasi laju kecepatan potongnya.

Tabel 3.2 Nilai kekasaran permukaan pada setiap Laju pemotongan

\begin{tabular}{|c|c|c|c|}
\hline \multirow[t]{2}{*}{$\begin{array}{c}\text { Laju } \\
\text { Pemotongan }\end{array}$} & \multirow[t]{2}{*}{ Pengukuran } & \multicolumn{2}{|c|}{$\begin{array}{l}\text { Hasil pengukuran } \\
\text { pada material uji }\end{array}$} \\
\hline & & $\overline{R a}(\mu \mathrm{m})$ & Rata-rata \\
\hline \multirow[t]{3}{*}{ Kecepatan a } & $\mathrm{I}$ & 0.231 & \\
\hline & II & 0.240 & 0.230 \\
\hline & III & 0.221 & \\
\hline \multirow[t]{3}{*}{ Kecepatan b } & 1 & 0.428 & \\
\hline & II & 0.431 & 0.423 \\
\hline & III & 0.411 & \\
\hline \multirow[t]{3}{*}{ Kecepatan c } & $T$ & 0.887 & \\
\hline & II & 0.876 & 0.875 \\
\hline & III & 0.862 & \\
\hline \multirow[t]{3}{*}{ Kecepatan d } & 1 & 1.187 & \\
\hline & II & 1.192 & 1.187 \\
\hline & IIII & 1.182 & \\
\hline \multirow[t]{3}{*}{ Kecepatan e } & $\mathrm{T}$ & 1.838 & \\
\hline & II & 1.851 & 1.851 \\
\hline & III & 1.863 & \\
\hline
\end{tabular}

Dari Tabel 3.2 terlihat bahwa nilai kekasaran yang paling kecil terjadi pada variasi laju pemotongan atau kecepatan a yaitu pada 153 $\mathrm{mm} / \mathrm{menit}$. Gerak makan atau laju pemotongan sangat berpengaruh terhadap nilai kekasaran. Peningkatan gerak makan atau laju pemotongan semakin meningkatkan nilai kekasaran. Hubungan linier antara gerak laju pemotongan dengan nilai kekasaran permukaan ditunjukkan secara grafis pada Gambar 4 di bawah ini

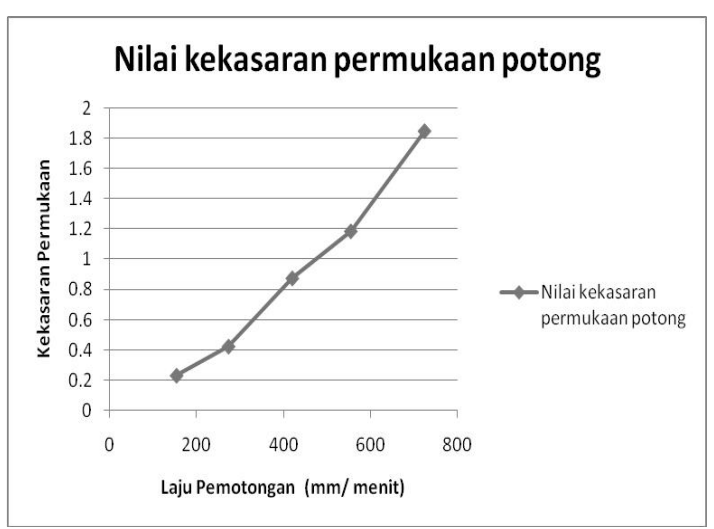

Gambar 4.5 Grafik Hubungan laju kecepatan pemotongan dengan Kekasaran Permukaan

Kecepatan laju pemotongan memberikan pengaruh terhadap kekasaran permukaan hasil pemotongan. Pada grafik 4.1 di atas terlihat laju kecepatan pemotongan $153 \mathrm{~mm} /$ menit memiliki nilai angka kekasaran rata -rata $(\mathrm{Ra})$ yang relatif kecil dan nilai angka kekasaran cenderung meningkat seiring bertambah besarnya nilai angka laju pemotongan.

\section{KESIMPULAN}

Kekasaran yang paling rendah dan menghasilkan angka kekasaran yang paling kecil ada di laju kecepatan pemotongan $153 \mathrm{~mm} /$ menit . Gerak laju kecepatan pemotongan mempengaruhi kekasaran permukaan hasil pemotongan, semakin rendah gerak laju kecepatan pemotongan akan menghasilkan nilai kekasaran yang lebih rendah. Besar Nilai Angka kekasaran pada laju kecepatan pemotongan 153 $\mathrm{mm} / \mathrm{menit}$ adalah $0.230 \mu \mathrm{m}$ 


\section{DAFTAR PUSTAKA}

[1] Dadang, Teknik Dasar Pengerjaan Logam , PPPPTK Boe Malang, 2013, hal. 108-109

[2] W. Harsono. Okumura Toshie, Teknologi Pengelasan Logam, Jakarta, 2000.

[3] Sonawan H., dan Suratman R., Pengantar untuk Memahami Proses Pengelasan Logam, Cetakan Kedua, CV Alfabeta, , Bandung, 2006

[4] Widharto S, Petunjuk Kerja Las, Cetakan Keenam, PT Pradnya Paramita, Jakarta,2006

[5] Wiryosumarto, H, Teknologi Pengelasan Logam, PT. Pradya Paramita, Jakarta, 2004

[6] Hobson, Tayor, Precision - Exploring Surface Texture, $3^{\text {rd }}$ edition March, 1998

[7] Standar ISO 1302 : 1996 dan Standar DIN $4768: 1981$ 